\title{
Performance evaluation of a multi-rotor unmanned agricultural aircraft system for chemical application
}

\author{
Hang Zhu ${ }^{1 *}$, Hongze Li ${ }^{1}$, Anderson P. Adam², Liujun Li ${ }^{2}$, Lei Tian ${ }^{2 *}$ \\ (1. Key Laboratory of CNC Equipment Reliability, Ministry of Education, School of Mechanical and Aerospace Engineering, \\ Jilin University, Changchun 130025, China; \\ 2. Department of Agricultural and Biological Engineering, University of Illinois at Urbana-Champaign, Urbana, IL 61801, USA)
}

\begin{abstract}
Unmanned agricultural aircraft system (UAAS) has been widely employed as a low-cost and reliable method to apply agrochemicals to small agricultural fields in China. The performance of battery-powered multirotor UAAS has attracted considerable attention from manufacturers and researchers. The objective of this research was to design a UAAS equipping with a data acquisition system, to characterize its chemical application performance based on droplet deposition data and optimize the operating parameters. Each test was repeated three times to assess the reliability of the spraying system. Various flight parameters were also evaluated. The optimal spray pressure for the XR8001 and XR8002 (TeeJet, Wheaton, IL, USA) nozzles was found to be $300 \mathrm{kPa}$, and the latter nozzle had a higher droplet deposition rate and spray volume. Spray volume was not significantly affected by the flight speed or droplet density and was negatively correlated with the nozzle pressure. The results of this study provide a basis for improving the efficiency of UAAS chemical application systems in terms of large-scale application.
\end{abstract}

Keywords: spray characterization, unmanned agricultural aircraft system, aerial sprayer, onboard data acquisition system, effective swath width, flight parameters, chemical application, performance evaluation

DOI: $10.25165 /$ j.ijabe.20211404.6194

Citation: Zhu H, Li H Z, Adam A P, Li L J, Tian L. Performance evaluation of a multi-rotor unmanned agricultural aircraft system for chemical application. Int J Agric \& Biol Eng, 2021; 14(4): 43-52.

\section{Introduction}

Current methods for applying agricultural chemicals in China are mostly manual or semi-mechanization ${ }^{[1-3]}$. However, the use of unmanned agricultural aircraft systems (UAAS) for pesticide application has increased in recent decades due to their flexibility and adaptability ${ }^{[4-7]}$. Compared to traditional methods of pesticide application, UAAS constitutes a low-cost, reliable, and easy-to-operate platform. To support the development and wide adoption of UAAS for aerial application of agricultural chemicals, analysis and evaluation of their performance under field conditions are required.

In recent years, UAAS for chemical application has been developed; however, little research has been conducted to characterize their performance and identify ideal operating parameters ${ }^{[8]}$. It is essential to understand the performance characteristics of such systems to improve the efficiency of large-scale applications. Due to the declining labor force in rural areas caused by rural-urban migration, UAAS platforms have

\section{Received date: 2020-10-07 Accepted date: 2021-01-12}

Biographies: Hongze Li, Master candidate, research interest: agricultural aviation application, Email: lihz18@mails.jlu.edu.cn; Anderson P. Adam, Master, research interest: agricultural aerial pesticide application, Email: apndrsn2@illinois.edu; Liujun Li, PhD, research interest: agricultural aviation and ground remote sensing, Email: liliujun.csu@gmail.com.

*Corresponding author: Hang $\mathbf{Z h u}, \mathrm{PhD}$, Associate Professor, research interest: intelligent machinery of precision agriculture and automatic control, precision agriculture aviation and equipment. School of Mechanical and Aerospace Engineering, Jilin University, 5988 Renmin Road, Changchun, China. Tel: +86-18088665997, Email: hangzhu@jlu.edu.cn; Lei Tian, PhD, Professor, research interest: develop precision and site-specific tools for the agriculture. Department of Agricultural and Biological Engineering, University of Illinois at Urbana-Champaign, IL 61801, Urbana, USA. Tel: +1-217-3337534, Email: lei-tian@illinois.edu. played an important role in improving farming efficiency ${ }^{[9]}$. Accordingly, research on the utility of UAAS for plant protection and disease management has increased ${ }^{[10]}$. Huang et al. ${ }^{[11]}$ presented an overview of research on UAAS for the management of agricultural production. Yang et al. ${ }^{[12]}$ discussed how airborne and satellite imagery and variable rate technology were used for detecting and mapping cotton root rot. Zhang et al. ${ }^{[13]}$ introduced a UAAS for plant protection in a maize field, suggesting that "stable visual semantic navigation" can be achieved under a "near color background". Wang et al. ${ }^{[14]}$ analyzed the weaknesses of existing plant protection UAAS. As a key component of UAAS, spray performance is attracting increasing attention. Wen et al. ${ }^{[15]}$ designed a pulse width modulation (PWM)-based variable spray system based on a UAAS, and showed that the system could adjust the spray flow rapidly according to the prescription map. Huang et al. ${ }^{[16]}$ developed a fully autonomous UAAS (helicopter) for low-volume application of crop protection products to specific crop areas. On-farm trials have also been conducted to investigate droplet drift characteristics. Thomsen et al. ${ }^{[17]}$ studied the influence of the "wake wind field" on the droplet deposition distribution of an Air-Tractor 402B aircraft (Air Tractor, Inc., Olney, TX, USA). The drift deposition and spray performance of UAAS have been also proven valuable. Brown et al. ${ }^{[18]}$ measured spray drift in the context of imidacloprid application over an $8400 \mathrm{~m}^{2}$ Napa Valley vineyard via an R-Max II aircraft (Yamaha, Shizuoka, Japan). Computational fluid dynamics (CFD) has been widely used to simulate the drift and motion of droplets. Zhu et al. ${ }^{[19]}$ established a "droplet drift model" based on CFD, according to the laws of droplet drift and deposition. Nuyttens et al. ${ }^{[20]}$ established a three-dimensional CFD-based spray drift model, which considered droplet characteristics, meteorological conditions, chemical and crop characteristics, and canopy structure. There have been some researches concerning the procedure of building 
spray system based on UAV and analyses of the spray droplet characteristics of UAAS, but relatively few in both building procedure and performance characteristics of the spray system. Thus, this study aimed to evaluate a newly designed UAAS for chemical application and characterize its spray pattern under different operating conditions.

\section{Materials and methods}

\subsection{Aerial sprayer and data acquisition system}

The aerial spray system (Figure 1) was based on the S1000 octocopter (DJI, Shenzhen, China), and consisted of an A2 Flight Controller (DJI), a ground station, a dry-boom sprayer system with TeeJet nozzles, a flex hose, a small diaphragm pump capable of pressurization up to $0.7 \mathrm{MPa}$ and a flexible liquid bladder. A bladder-equipped polyurethane (PU) water pipe was connected beneath the UAAS body using a suspension system, and the pump was mounted below the bladder. The two nozzles were mounted on nozzle bodies spaced $55.88 \mathrm{~cm}$ apart and bolted onto the retractable landing gear. The spray system was controlled by an Arduino Zero microcontroller ${ }^{[21,22]}$, which is a convenient and easy-to-use open-source electronic control platform. The altitude was measured using a light detection and ranging (LiDAR) sensor, and video data were acquired during flight tests to compensate for the low accuracy of global positioning system (GPS) data ${ }^{[23,24]}$. All flights were controlled by a DX7 transmitter (Spektrum, Champaign, IL, USA) and lateral position was estimated using the video data acquired during the flights.

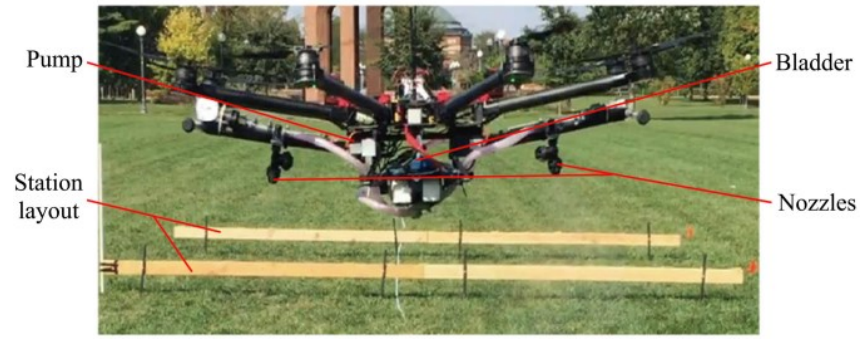

Figure 1 Aerial spray system based on a DJI S1000 octocopter

Data were collected from a weather station, cameras, and an onboard data acquisition system (ODAQ). The ODAQ was integrated to control the circuit of UAV for the purpose of collecting information and controlling the whole system. The weather station, consisting of a microcontroller and various sensors, was located near the study site; the components and parameters are listed in Table 1. The wind speed, wind direction, barometric pressure, temperature, and humidity were collected simultaneously by an anemometer, wind vane, barometer, temperature sensor, and hygrometer $^{[25,26]}$. The ODAQ (Figure 2) data were used to evaluate the flight characteristics; the components and parameters are listed in Table 2. A single point LiDAR module was connected to the front of the UAAS for real-time height estimation. An XBee wireless transmitter was connected to an Arduino Uno microcontroller, allowing data transmission to the weather station and cameras for data syncing during the tests. A secure digital (SD) card reader was used for onboard data storage. The PWM (Pulse Width Modulation) signal was generated by the microcontroller and amplified by a metal-oxide-semiconductor field-effect transistor (MOSFET) to control the DC pump motor speed through a D/A output terminal and a servo board analog output. The PWM-based variable spray system allowed control of the pump speed according to the inlet pressure of the nozzles ${ }^{[27,28]}$. The calibration of inlet pressure under the control of PWM has been carried out in the laboratory. A smartphone camera connected to a Raspberry Pi 3 single-board computer was used to record video for estimation of flight parameters (flight speed, etc. $)^{[29-31]}$. Trigger signals were initialized by the weather station through a Python script ${ }^{[32]}$; after receiving the trigger, the camera recorded a video of $30 \mathrm{~s}$ clip and transferred it to an external drive.

Table 1 Weather station components and parameters

\begin{tabular}{cclc}
\hline Component & \multicolumn{1}{c}{ Function } & \multicolumn{1}{c}{ Parameter/unit } & Value \\
\hline $\begin{array}{c}\text { Arduino } \\
\text { Uno }\end{array}$ & Microcontroller & $\begin{array}{l}\text { Clock speed/MHz } \\
\text { Storage/kB }\end{array}$ & 16 \\
\hline SHT15 & $\begin{array}{c}\text { Temperature and } \\
\text { humidity measurement }\end{array}$ & $\begin{array}{l}\text { Temperature accuracy } /{ }^{\circ} \mathrm{C} \\
\text { RH accuracy } / \%\end{array}$ & 0.3 \\
\hline MPL3115A2 & $\begin{array}{c}\text { Barometric pressure } \\
\text { measurement }\end{array}$ & Pressure accuracy $/ \mathrm{Pa}$ & 2 \\
\hline P/N80422 & $\begin{array}{c}\text { Wind speed and } \\
\text { direction measurement }\end{array}$ & Wind directions & 3.6 \\
\hline WBee 60mW & $\begin{array}{c}\text { Wireless data } \\
\text { communication }\end{array}$ & $\begin{array}{l}\text { Max communication rate } / \mathrm{kb} \cdot \mathrm{s}^{-1} \\
\text { Communication range } / \mathrm{m}\end{array}$ & 250 \\
\hline Note: $\mathrm{RH}$ represents relative humidity & 1609 \\
\hline which describes the degree of drying.
\end{tabular}

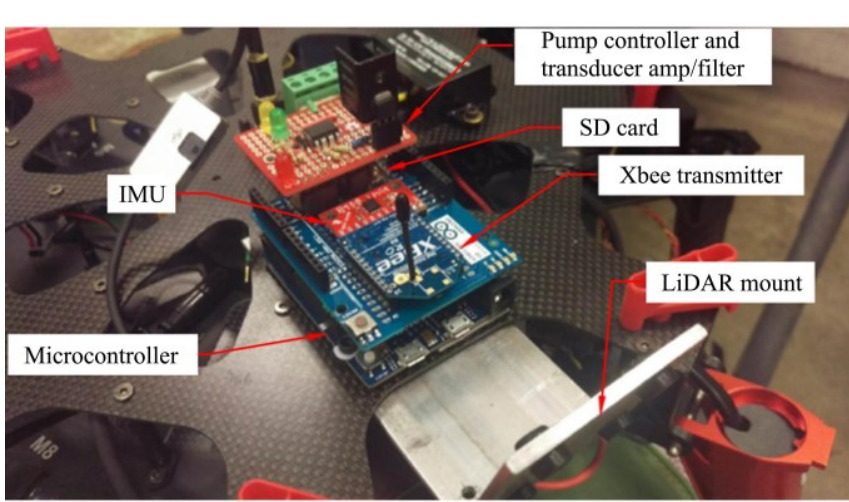

Note: IMU is an inertial measurement unit that can measure speed and acceleration.

Figure 2 Onboard data acquisition system

Table 2 ODAQ components and parameters

\begin{tabular}{|c|c|c|c|}
\hline Components & Function & Parameter/unit & Value \\
\hline \multirow{3}{*}{ Arduino Zero } & \multirow{3}{*}{ Microcontroller } & Clock speed/MHz & 48 \\
\hline & & Storage $/ \mathrm{kB}$ & 32 \\
\hline & & $\mathrm{ADC}$ resolution/bit & 12 \\
\hline \multirow{3}{*}{ MPU9150 } & \multirow{3}{*}{$\begin{array}{c}\text { Inertial } \\
\text { measurement unit }\end{array}$} & Communication rate $/ \mathrm{kHz}$ & 400 \\
\hline & & Tri-axis compass range/T & \pm 1200 \\
\hline & & Tri-axis accelerometer range/g & $\pm(2-16)$ \\
\hline \multirow{3}{*}{ LiDAR Lite } & \multirow{3}{*}{$\begin{array}{c}\text { Distance } \\
\text { measurement }\end{array}$} & Distance/cm & 2.5 \\
\hline & & Measurement range $/ \mathrm{m}$ & $0-40$ \\
\hline & & Acquisition time/s & 0.02 \\
\hline \multirow{2}{*}{$\mathrm{XBee} 60 \mathrm{~mW}$} & \multirow{2}{*}{$\begin{array}{l}\text { Wireless data } \\
\text { communication }\end{array}$} & Communication range $/ \mathrm{m}$ & 1600 \\
\hline & & Communication rate $/ \mathrm{kb} \cdot \mathrm{s}^{-1}$ & 250 \\
\hline \multirow{2}{*}{$\begin{array}{c}\text { Arduino } \\
\text { Wireless SD }\end{array}$} & \multirow{2}{*}{ Data storage } & Communication range $/ \mathrm{m}$ & 900 \\
\hline & & Working voltage/V & 5 \\
\hline
\end{tabular}

\subsection{Spray test experimental design}

All tests were performed in an outdoor environment to ensure realistic conditions and therefore also adhered to typical guidelines for application environmental conditions. Testing was avoided when wind velocities exceeded $5 \mathrm{~m} / \mathrm{s}$, attempting to carry out most tests under $3 \mathrm{~m} / \mathrm{s}$ since most of the nozzles being used produced a smaller droplet spectrum. The ideal conditions are a wind speed of less than $3 \mathrm{~m} / \mathrm{s}$, to minimize the drift potential, and an air temperature of under $25^{\circ} \mathrm{C}$ to minimize evaporation ${ }^{[33-36]}$. There 
were three spraying tests (Series 1-3) with different parameters (nozzle pressure and type); these were further divided into Tests 1-4, and Passes 1-3, as described in the following sections.

\subsubsection{Pre-test}

A pre-test was performed to determine the initial parameters for future tests and assess the analysis method. Based on the results of the pre-test, a flight line was established, the UAAS would be equipped with two different nozzles and flown along this flight line while spraying, varying the pressure for each flight. Three frames (S1-S3) were $2.40 \mathrm{~m} \times 0.03 \mathrm{~m}$, fixed on either end by brackets, allowing them to be staked into the ground and the levels were arranged at regular intervals along the $30 \mathrm{~m}$ flight path
(Figure 3a). Each test was repeated along all three sampling lines. Each sampling point was separated by $0.3 \mathrm{~m}$. Rigid, yellow water-sensitive paper ( $76 \mathrm{~mm} \times 26 \mathrm{~mm}$; CH-4002; Syngenta, Basel, Switzerland) that is stained dark blue by water droplets were placed at each sampling point, at a height of $0.2 \mathrm{~m}$. The stations described in this test contained an array of water-sensitive paper spaced according to Figure $3 \mathrm{~b}$. The spacing decided for this test series was $0.3 \mathrm{~m}$. The estimated pattern width for a pair of $80^{\circ}$ nozzles with a spacing of $0.5 \mathrm{~m}$ at the suggested flight height of $0.76 \mathrm{~m}$ is approximately $1.5 \mathrm{~m}$. The test flights crossed all sampling lines to simulate actual spray conditions and were conducted $0.8 \mathrm{~m}$ above the water-sensitive paper.
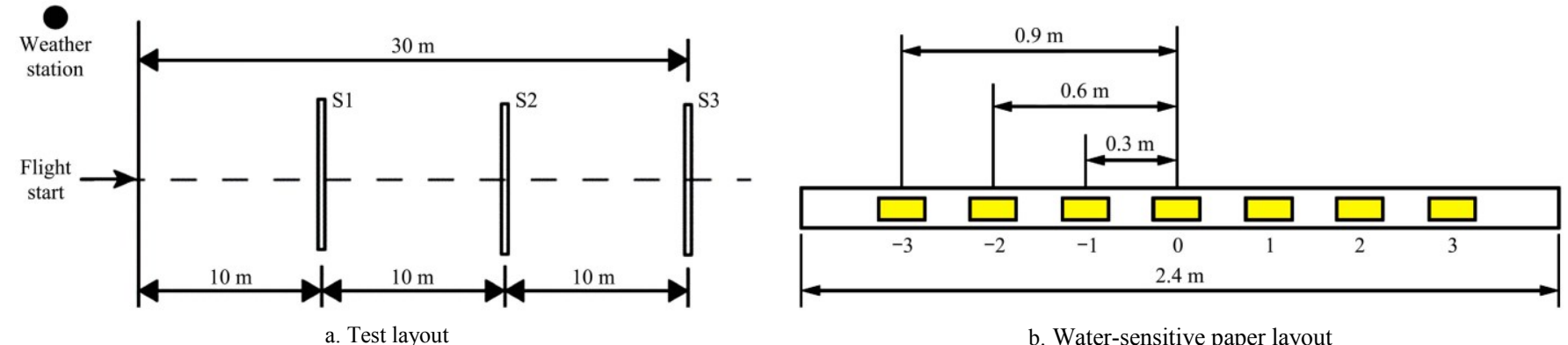

b. Water-sensitive paper layout

Figure 3 Three frames used to collect the deposited droplets

The Extended Range (XR) series of nozzles (TeeJet, Wheaton, IL, USA) have been widely used in agriculture due to their high performance $^{[37-40]}$. The XR8001 flat-fan nozzle (Figure 4) produces an even spray distribution ideal for initial testing. This nozzle has a single orifice at which fluid flow is controlled and the droplets are produced. The droplet volume (DV) and density can be controlled by varying the pressure of the inlet, with droplets decreasing in size and quantity as the pressure is increased ${ }^{[41]}$.

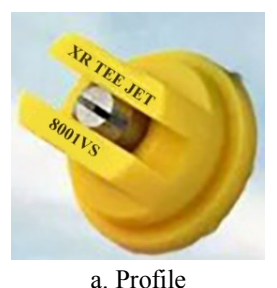

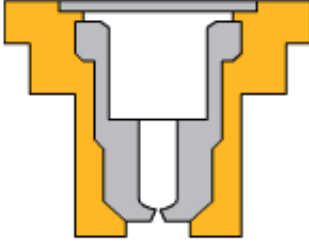

b. Elevation view
Figure 4 XR series 8001VS nozzle (TeeJet)

\subsubsection{Experimental Series 1}

The purpose of Series 1 tests was to identify the effects of pressure variation on droplet density and deposition using two different-sized nozzles (XR8001 and XR8002). Series 1 included eight nozzle size/pressure combinations which are listed in Table 3.

\subsubsection{Experimental Series 2}

The purpose of Series 2 tests was to determine the effective swath width of the UAAS for different nozzle types (Table 4). Each test was repeated three times to ensure accurate results.

\subsubsection{Experimental Series 3}

Series 3 tests were designed to identify the effects of flight speed, nozzle type, and inlet pressure on spray characteristics (Table 5). Flight speeds in the range of $3-5 \mathrm{~m} / \mathrm{s}$ and $7-9 \mathrm{~m} / \mathrm{s}$ were defined as "slow" and "fast", respectively; it was not possible to configure the UAAS flight speed more precisely.

Table 3 Series 1 test configurations

\begin{tabular}{|c|c|c|c|c|c|c|c|c|}
\hline Variable & Test 1 & Test 2 & Test 3 & Test 4 & Test 5 & Test 6 & Test 7 & Test 8 \\
\hline Nozzle & XR8001 & XR8001 & XR8001 & XR8001 & XR8002 & XR8002 & XR8002 & XR8002 \\
\hline Pressure $/ \mathrm{kPa}$ & 100 & 200 & 300 & 400 & 100 & 200 & 300 & 400 \\
\hline
\end{tabular}

Table 4 Series 2 test configurations

\begin{tabular}{cccccc}
\hline Variable & Test 1 (1) & Test 1 (2) & Test 1 (3) & Test 2 (1) & Test 2 (2) \\
\hline Passes & Pass 1 & Pass 2 & Pass 3 & Pass 1 & Pass 2 \\
Pozzle & XR8001 & XR8001 & XR8001 & XR8002 & XR8002 \\
\hline
\end{tabular}

Table 5 Series 3 test configurations

\begin{tabular}{ccccccccccccc}
\hline Variable & Test 1 & Test 2 & Test 3 & Test 4 & Test 5 & Test 6 & Test 7 & Test 8 & Test 9 & Test 10 & Test 11 & Test 12 \\
\hline Nozzle & XR8001 & XR8001 & XR8001 & XR8002 & XR8002 & XR8002 & XR8001 & XR8001 & XR8001 & XR8002 & XR8002 & XR8002 \\
Pressure/kPa & 200 & 300 & 400 & 200 & 300 & 400 & 200 & 300 & 400 & 200 & 300 & 400 \\
Speed $/ \mathrm{m} \cdot \mathrm{s}^{-1}$ & $3-5$ & $3-5$ & $3-5$ & $3-5$ & $3-5$ & $3-5$ & $7-9$ & $7-9$ & $7-9$ & $7-9$ & $7-9$ & $7-9$ \\
\hline
\end{tabular}

\subsection{Analysis method}

Droplet analysis was performed using the DepositScan program of the United States Department of Agriculture (USDA $)^{[42-45]}$. The program is designed to identify droplets and measure their size and quantity, in conjunction with a handheld scanner with a resolution of $600 \mathrm{dpi}$. After the completion of each test, all sample cards were collected into a labeled Ziplock bag and labeled. The cards were then scanned to record the sizes and 
quantities of droplets. The spray pattern in each test was analyzed according to the following parameters.

DV $(\mu \mathrm{m})$. All detected droplets were sorted from smallest to largest; then, the DV was summed across all droplets. $\mathrm{D}_{\mathrm{V} 0.1}$ represents the volume of a small droplet $(10 \%$ of the total deposited volume). $\quad \mathrm{D}_{\mathrm{V} 0.5}$ and $\mathrm{D}_{\mathrm{V} 0.9}$ represent the volume of medium-sized and large droplets, respectively ${ }^{[46,47]}$.

Droplet density (number of droplets $/ \mathrm{cm}^{2}$ ). The area density of droplets has an important influence on the efficacy of pesticides, including insecticides, fungicides and herbicides.

Droplet deposition $\left(\mathrm{L} / \mathrm{hm}^{2}\right)$. This parameter provides an estimate of the DV within a given region and is calculated as the sum of the DV divided by the surface area. Deposition provides insight into the size of the droplets relative to the density ${ }^{[48]}$.

Effective swath width (m). This parameter is determined according to the distance between two points and represents half of the maximum deposition rate according to the deposition curve, which was drawn based on sample points located at either end of the flight route.

CV (\%) - Coefficient of Variation is a measure of the continuity of a spray pattern and can be obtained from Equation (1).

$$
C V=\frac{\sigma}{\mu} \times 100 \%
$$

where, $\sigma$ is the standard deviation and $\mu$ is the mean.

The results of the Series 1-3 tests can be used to evaluate the performance of the UAAS aerial sprayer and the spray characteristics. Comparison with laboratory results, and with those provided by the nozzle manufacturer, can provide further insight into the performance of the UAAS aerial sprayer.

\section{Results}

To investigate the effect of different spray and flight conditions, including nozzle pressure, flight speed, and effective swath width, on the chemical application performance parameters (DV, droplet density, and droplet deposition), the water-sensitive paper samples were scanned and the spray patterns were analyzed.

\subsection{Effect of spraying pressure and nozzle type: Series 1}

3.1.1 Effect of spraying pressure and nozzle type on droplet volume

Series 1 was designed to investigate the relationship between nozzle pressure and DV; the results are presented in Figure 5. The $X$-axis indicates the pressure of the nozzle inlet. The $Y$-axis shows the DV $(\mu \mathrm{m})$. Each line represents a different DV.

It is clear that, in general, the DV $\left(\mathrm{D}_{\mathrm{V} 0.1}, \mathrm{D}_{\mathrm{V} 0.5}, \mathrm{D}_{\mathrm{V} 0.9}\right)$ decreases as the pressure increases. The two types of nozzles showed the same tendency in terms of the relationship between pressure and DV. However, an interesting phenomenon observed was that DV appeared minor shift; this may be because the actual pressure was lower than $400 \mathrm{kPa}$ due to a poor seal at the pipe connection point. The least-squares method was used to fit the $\mathrm{D}_{\mathrm{V} 0.1}\left(y_{1}\right), \mathrm{D}_{\mathrm{V} 0.5}\left(y_{2}\right)$ and $\mathrm{D}_{\mathrm{V} 0.9}\left(y_{3}\right)$ data under the two different pressures $\left(x_{1}, x_{2}\right)$ (Table 6$)$.

The pressure was negatively correlated with all DVs. For every $100 \mathrm{kPa}$ increase in the XR8001 nozzle pressure, $\mathrm{D}_{\mathrm{V} 0.1}$ decreased by $12.8 \%, \mathrm{D}_{\mathrm{V} 0.5}$ decreased by $12.5 \%$, and $\mathrm{D}_{\mathrm{V} 0.9}$ decreased by $10.3 \%$. For every $100 \mathrm{kPa}$ increase in the XR8002 nozzle pressure, $\mathrm{D}_{\mathrm{V} 0.1}$ decreased by $14.7 \%, \mathrm{D}_{\mathrm{V} 0.5}$ decreased by $16.8 \%$ and $\mathrm{D}_{\mathrm{V} 0.9}$ decreased by $16.6 \%$. $\quad \mathrm{D}_{\mathrm{V} 0.5}$ for XR8002 and XR8001 had a minimum value of $292 \mu \mathrm{m}$ and $341 \mu \mathrm{m}$, respectively, at a pressure of $300 \mathrm{kPa}$. The absolute value of the coefficient for the primary term $\left(\mathrm{D}_{\mathrm{V} 0.1}, \mathrm{D}_{\mathrm{V} 0.5}, \mathrm{D}_{\mathrm{V} 0.9}\right)$ increased, indicating that the degree of influence also increased.

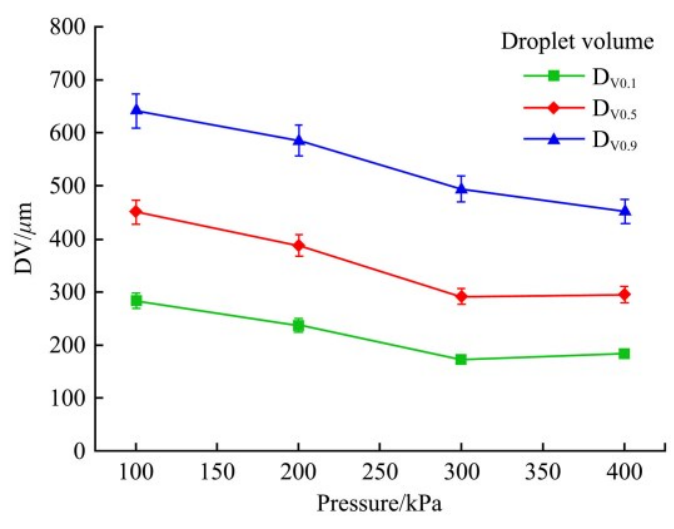

a. XR8001

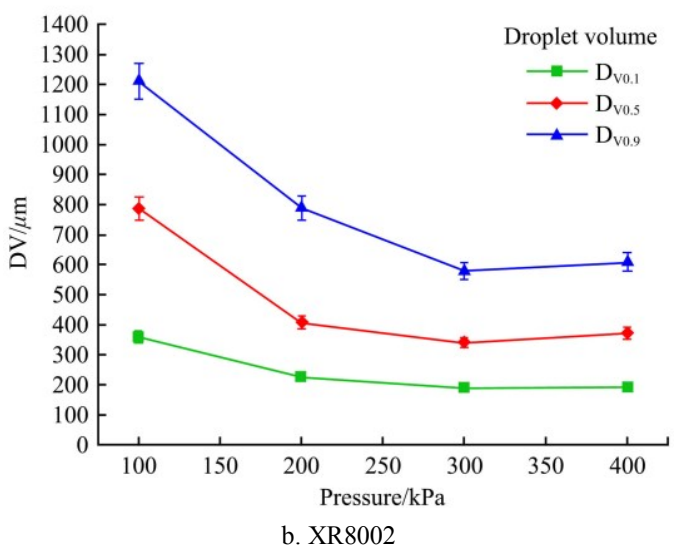

Figure 5 Droplet volume (DV; $\left.\mathrm{D}_{\mathrm{V} 0.1}, \mathrm{D}_{\mathrm{V} 0.5}, \mathrm{D}_{\mathrm{V} 0.9}\right)$ by pressure for two nozzle types

Table 6 Droplet volume models

\begin{tabular}{cclc}
\hline Nozzle type & Droplet volume & \multicolumn{1}{c}{ Model } & $R^{2}$ \\
\hline \multirow{3}{*}{ XR8001 } & $\mathrm{D}_{\mathrm{V} 0.1}$ & $y_{1}=-36.352 x_{1}+310.79$ & 0.834 \\
& $\mathrm{D}_{\mathrm{V} 0.5}$ & $y_{2}=-56.4 x_{1}+497.93$ & 0.887 \\
& $\mathrm{D}_{\mathrm{V} 0.9}$ & $y_{3}=-66.276 x_{1}+709.93$ & 0.982 \\
\hline \multirow{3}{*}{ XR8002 } & $\mathrm{D}_{\mathrm{V} 0.1}$ & $y_{4}=-52.86 x_{2}+375.06$ & 0.775 \\
& $\mathrm{D}_{\mathrm{V} 0.5}$ & $y_{5}=-132.24 x_{2}+804.73$ & 0.658 \\
& $\mathrm{D}_{\mathrm{V} 0.9}$ & $y_{6}=-201.276 x_{2}+1302$ & 0.801 \\
\hline
\end{tabular}

3.1.2 Effect of nozzle pressure and type on droplet density

The droplet density at different sample points for the XR8001 and XR8002 nozzles is shown in Figure 6. The $X$-axis indicates the sample points and the $Y$-axis indicates the droplet density. Each line represents a different pressure $(100,200,300,400 \mathrm{kPa})$. The corresponding flight and environmental information are provided in Table 7.

As shown in Table 7, all tests were carried at flight speeds of 4.50 to $6.40 \mathrm{~m} / \mathrm{s}$, flight height of 0.79 to $0.93 \mathrm{~m}$, wind speed of 1.18 to $2.50 \mathrm{~m} / \mathrm{s}$ and the average temperature was $30.54^{\circ} \mathrm{C}$, average $\mathrm{RH}$ was $44.03 \%$ and average pressure was $99358 \mathrm{~Pa}$. The correlation coefficient between the pressure and droplet density was 0.72 . Excessive pressure leads to an uneven droplet distribution in the target area, as shown by the density curves. For XR8001 in $100 \mathrm{kPa}, 200 \mathrm{kPa}, 300 \mathrm{kPa}$ and $400 \mathrm{kPa}$, the number of sample card over 10 droplets $/ \mathrm{cm}^{2}$ in density were $0,0,6$ and 3; the uniformity of droplet density were $15.4 \%, 20.5 \%, 42.8 \%$ and $77.5 \%$; the average were 4.8, 5.0, 17.4 and 14.2 droplets $/ \mathrm{cm}^{2}$, respectively. For XR8002 in $100 \mathrm{kPa}, 200 \mathrm{kPa}, 300 \mathrm{kPa}$ and $400 \mathrm{kPa}$, the 
number of sample card over 10 droplets $/ \mathrm{cm}^{2}$ in density were $0,7,7$ and 7 ; the uniformity of droplet density were $27.5 \%, 68.7 \%, 31.6 \%$ and $32.8 \%$; the average were $7.0,17.9,32.0$ and 39.6 droplets $/ \mathrm{cm}^{2}$, respectively. The results indicated that $300 \mathrm{kPa}$ was the optimal spray pressure for nozzles XR8001 and XR8002, with the latter nozzle producing a greater droplet density at this pressure.

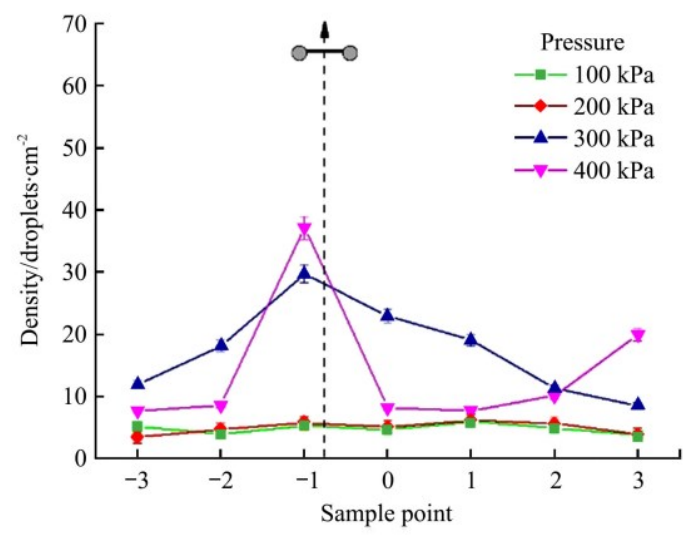

a. XR8001

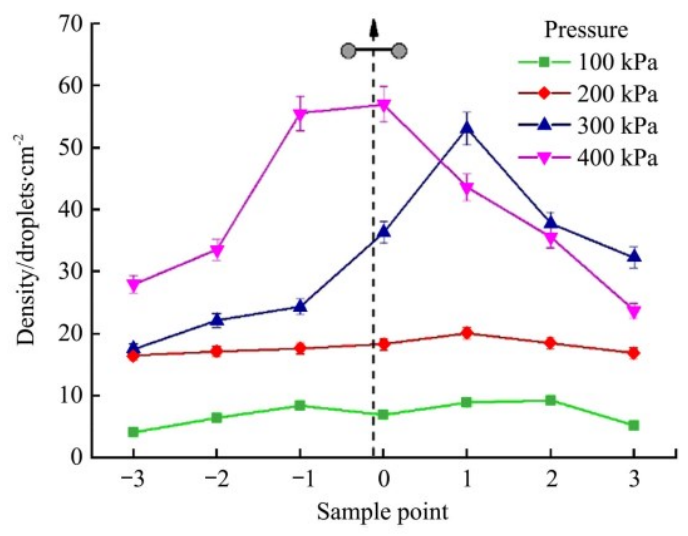

b. XR8002

Note: The flight path is represented by the black dotted line, and the two grey dots represent the spacing of the two nozzles, the same as below.

Figure 6 Density (droplets $/ \mathrm{cm}^{2}$ ) at different sample points for the two nozzle types under different nozzle pressures

Table 7 Flight and environmental data collected by the data acquisition system for Tests 1-8 in Series 1

\begin{tabular}{cccccccc}
\hline Test & $\begin{array}{c}\text { Speed } \\
/ \mathrm{m} \cdot \mathrm{s}^{-1}\end{array}$ & $\begin{array}{c}\text { Height } \\
/ \mathrm{m}\end{array}$ & $\begin{array}{c}\text { Wind speed } \\
/ \mathrm{m} \cdot \mathrm{s}^{-1}\end{array}$ & $\begin{array}{c}\text { Wind } \\
\text { direction }\end{array}$ & $\begin{array}{c}\text { Temperature } \\
/{ }^{\circ} \mathrm{C}\end{array}$ & $\begin{array}{c}\mathrm{RH} \\
/ \%\end{array}$ & $\begin{array}{c}\text { Pressure } \\
/ \mathrm{Pa}\end{array}$ \\
\hline Test 1 & 6.40 & 0.79 & 2.05 & $\mathrm{NE}$ & 32.40 & 40.93 & 99446 \\
Test 2 & 4.67 & 0.86 & 0.98 & $\mathrm{SW}$ & 28.81 & 48.40 & 99334 \\
Test 3 & 5.34 & 0.84 & 1.34 & $\mathrm{NW}$ & 29.31 & 48.23 & 99451 \\
Test 4 & 4.74 & 0.93 & 1.53 & $\mathrm{~W}$ & 28.10 & 47.86 & 99334 \\
Test 5 & 4.50 & 0.84 & 2.50 & $\mathrm{NW}$ & 30.86 & 42.12 & 99350 \\
Test 6 & 4.66 & 0.86 & 1.72 & $\mathrm{SE}$ & 31.49 & 42.29 & 99315 \\
Test 7 & 4.72 & 0.83 & 1.56 & $\mathrm{SE}$ & 31.56 & 41.85 & 99325 \\
Test 8 & 4.84 & 0.84 & 1.18 & $\mathrm{~W}$ & 31.79 & 40.54 & 99309 \\
\hline
\end{tabular}

Note: RH represents relative humidity which describes the degree of drying.

3.1.3 Effect of nozzle pressure and type on droplet deposition

The droplet deposition at the different sample points is shown in Figure 7. The $X$-axis indicates the sample points and the $Y$-axis indicates the droplet deposition. The different-colored columns represent the various pressures.

There was no significant relationship between nozzle pressure and droplet deposition due to the correlation coefficient was 0.17 . For XR8001 in $100 \mathrm{kPa}, 200 \mathrm{kPa}, 300 \mathrm{kPa}$ and $400 \mathrm{kPa}$, the uniformity of droplet deposition were $33.1 \%, 29.6 \%, 33.9 \%$ and
$58.5 \%$ respectively. For XR8002 in $100 \mathrm{kPa}, 200 \mathrm{kPa}, 300 \mathrm{kPa}$ and $400 \mathrm{kPa}$, the uniformity of droplet deposition were $43.5 \%$, $16.3 \%, 36.1 \%$ and $40.9 \%$ respectively. The deposition of nozzle XR8002 was greater than that of nozzle XR8001 under the same conditions; this is likely because an increase in pressure results in a corresponding increase in droplet density and decrease in DV, resulting in little change in the total deposition. This can be observed from the DV and density curves shown in Figures 6 and 7 However, the DVs and droplet densities for nozzle XR8002 are all greater than those for nozzle XR8001, resulting in a higher droplet deposition rate.

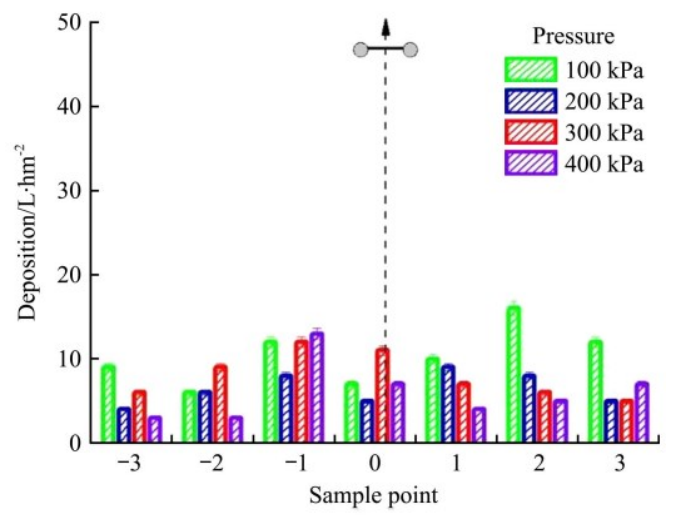

a. XR8001

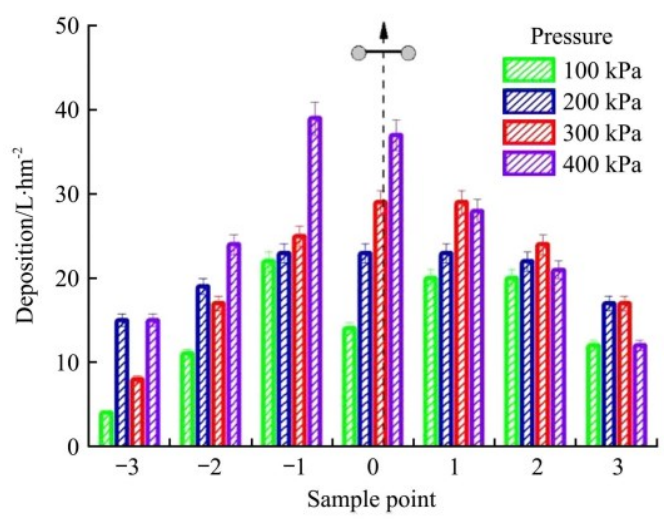

b. XR8002

Note: The flight path is represented by the black dotted line, and the two grey dots represent the spacing of the two nozzles.

Figure 7 Deposition of droplets $\left(\mathrm{L} / \mathrm{hm}^{2}\right)$ by sample point for nozzle types under different nozzle pressures

\subsubsection{Correlation matrix}

A correlation matrix was used as a simple method to quickly identify major influencing factors from the test data, as tests were numerous as was the amount of data collected. These influencing factors are then plotted to visualize the trend and further assess its behavior. The correlation matrix identifies linear relationships between variables. It is symmetric and establishes relationships between variables via Equation (2).

$$
\rho_{i j}=\frac{\sigma_{i j}}{\sqrt{\sigma_{i i} \sigma_{i j}}}
$$

where, $\sigma$ is the standard deviation; $\rho$ is the correlation coefficient; $i$ and $j$ are the row and column position, respectively. Table 8 for Series 1 is the output of a correlation matrix comparing the spray pattern characteristics to the operation parameters selected for the UAAS. The output utilized data from all tests from Series 1. The values in the cells indicate the linear association, with 1 being the highest possible value (which is why variables compared to themselves all have a value of 1) and 0 suggesting independence. 
Positive and negative values indicate the slope of the trend line. It should be noted that since this method is only valid for linear relationships it cannot be assumed that uncorrelated variables are not related at all, while it's simply a method of identifying relationships that warrants further analysis. The data gained from a single station is not sufficient to make any conclusions, and they are simply used to demonstrate an example of the findings of the correlation matrices and plots.

Table 8 Series 1 correlation matrix

\begin{tabular}{cccccccc}
\hline Parameter & A & B & C & D & E & F & G \\
\hline A & 1 & 0.18 & -0.01 & 0.24 & 0.43 & 0.67 & 0.90 \\
B & 0.18 & 1 & -0.85 & -0.70 & -0.67 & 0.72 & 0.17 \\
C & -0.01 & -0.85 & 1 & 0.95 & 0.88 & -0.59 & -0.05 \\
D & 0.24 & -0.70 & 0.95 & 1 & 0.96 & -0.40 & 0.11 \\
E & 0.43 & -0.67 & 0.88 & 0.96 & 1 & -0.29 & 0.27 \\
F & 0.67 & 0.72 & -0.59 & -0.40 & -0.29 & 1 & 0.78 \\
G & 0.90 & 0.17 & -0.05 & 0.11 & 0.27 & 0.78 & 1 \\
\hline
\end{tabular}

represents $\mathrm{D}_{\mathrm{V} 0.5} ; \mathrm{E}$ represents $\mathrm{D}_{\mathrm{V} 0.9} ; \mathrm{F}$ represents density; $\mathrm{G}$ represents deposition.

A strong positive correlation between flow rate and deposit density, flow rate and deposition can be seen from Table 8, respectively. Flow rate is a variable taken from the table of nozzle characteristics, for each nozzle, and is pressure dependent. The only reason they are not correlated at a value of 1 is due to the fact that the XR8001 and XR8002 nozzles produce different flow rates at the same pressures, because of orifice size.

Another strong negative correlation between DV and pressure
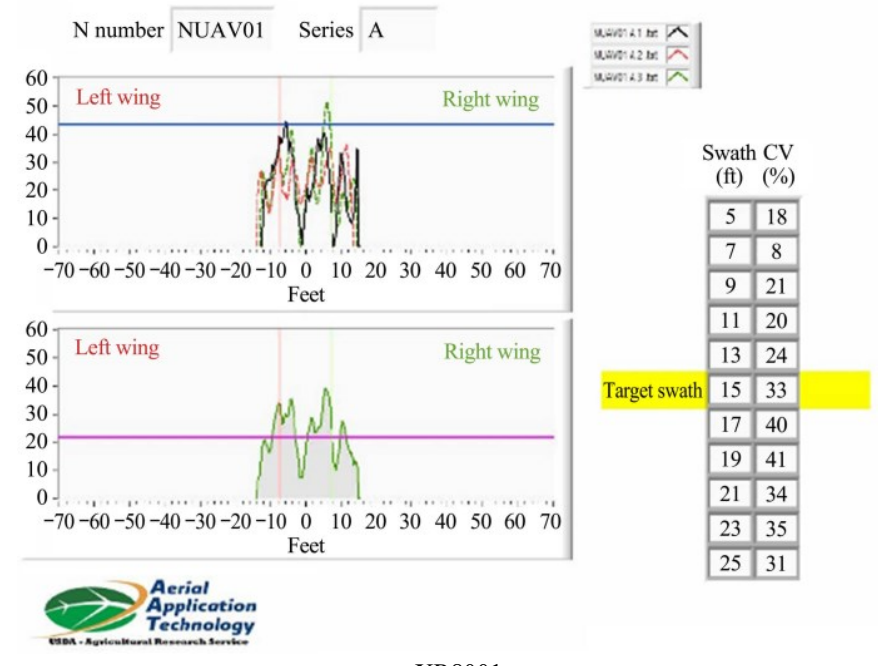

a. XR8001 can be seen. As pressure increases with the tested nozzles, droplet size decreases, this indicates the spray pattern generally followed the expected behavior. Increasing pressure had a much stronger influence on the $\mathrm{D}_{\mathrm{V} 0.1}$ droplet diameter (generally the smallest droplets in the spectrum) than $\mathrm{D}_{\mathrm{V} 0.5}$ or $\mathrm{D}_{\mathrm{V} 0.9}$, implying droplets representing the lowest $10 \%$ experienced a more significant shift than the larger $90 \%$.

\subsection{Effective swath width: Series 2}

Software provided by the Aerial Application Technology workgroup (United States Department of Agriculture; USDA) was used to analyze the spray patterns. The results obtained from the three passes of Tests 1 and 2 are shown in Figure 8. The figures in the bottom panels show the average values of three passes; the $X$-axis indicates the sample points and the $Y$-axis indicates droplet density. The effective swath width and $\mathrm{CV}$ are shown on the right The effective swath width was approximately $4.5 \mathrm{~m}$, based on the distance between the two points representing $50 \%$ of the peak density. A leftward bias can be seen in the averaged pattern, indicating possible droplet drift after release from the nozzles due to the effect of crosswinds.

\subsection{Effect of flight speed: Series 3}

3.3.1 Effect of flight speed on droplet volume

Series 3 was designed to investigate the effect of flight speed on DV (Figure 9). The $X$-axis indicates the nozzle inlet pressures $(200,300,400 \mathrm{kPa})$. The $Y$-axis indicates the DV $(\mu \mathrm{m})$. The three lines represent different droplet concentrations.

There does not appear to be an obvious difference in droplet volumes $\left(\mathrm{D}_{\mathrm{V} 0.1}, \mathrm{D}_{\mathrm{V} 0.5}, \mathrm{D}_{\mathrm{V} 0.9}\right)$ between tested speeds, which indicates it does not obviously differ by flight speed.

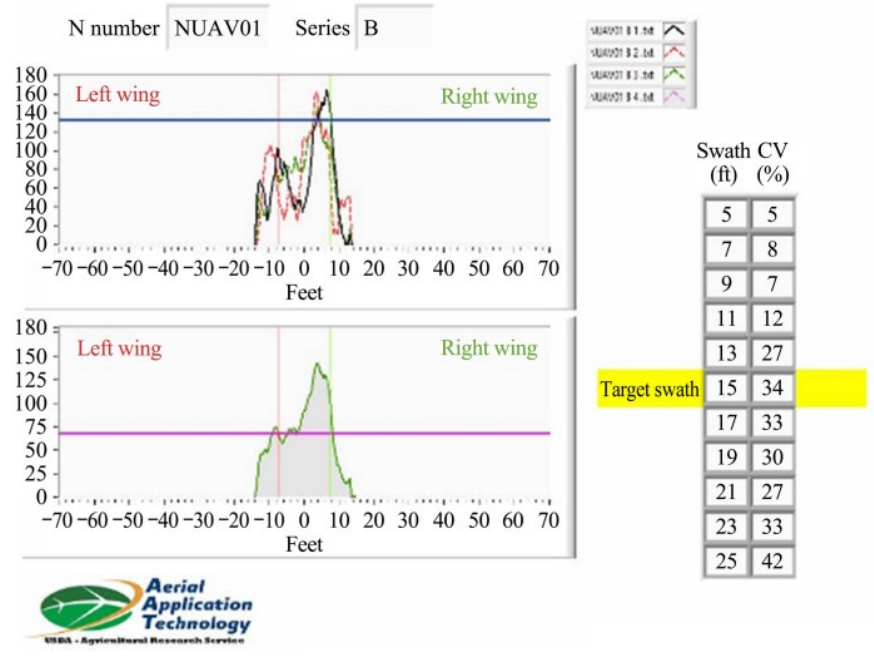

b. XR8002

Figure 8 Effective swath width of nozzles

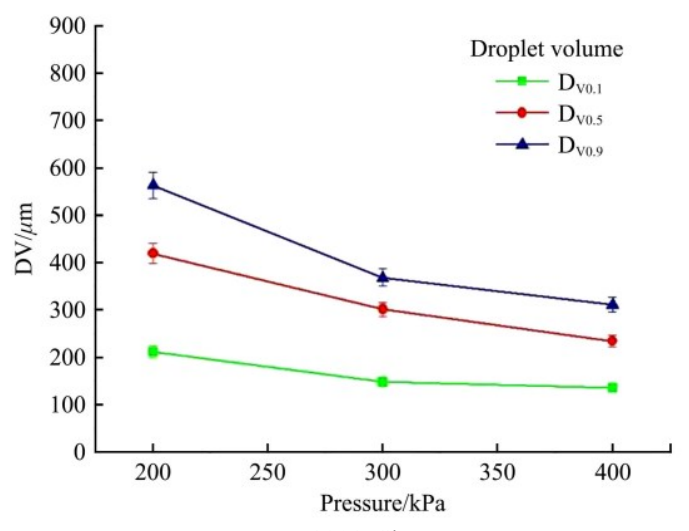

a. XR8001_Slow

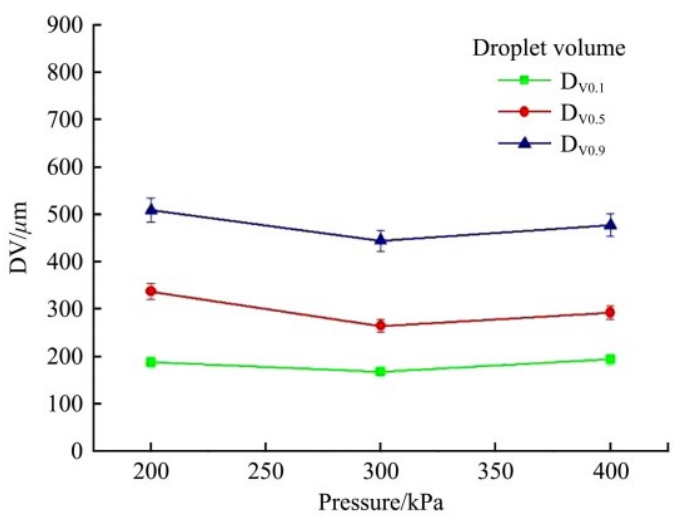

b. XR8001_Fast 

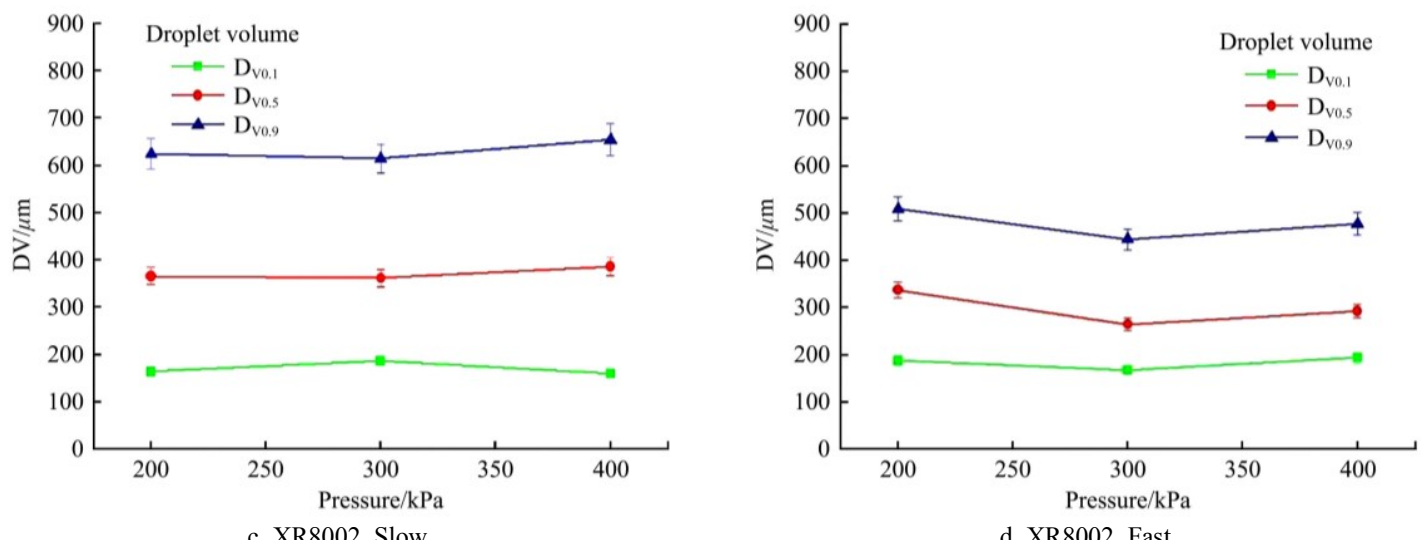

d. XR8002 Fast

Figure 9 Droplet volume (DV; $\left.\mathrm{D}_{\mathrm{V} 0.1}, \mathrm{D}_{\mathrm{V} 0.5}, \mathrm{D}_{\mathrm{V} 0.9}\right)$ by pressure for different nozzle types and flight speed conditions

\subsubsection{Effect of flight speed on droplet density}

The droplet density at each sample point for different nozzle types and flight speed conditions is shown in Figure 10. Flight and environmental information are provided in Table 9. The $X$-axis indicates the sample points and the Y-axis represents droplet density. The three colored lines represent different nozzle pressures $(200,300$, and $400 \mathrm{kPa})$.

As shown in Table 9, all tests were carried at flight speeds of 3.54 to $4.07 \mathrm{~m} / \mathrm{s}$ (slow), 7.12 to $8.33 \mathrm{~m} / \mathrm{s}$ (fast), flight height of 0.69 to $1.25 \mathrm{~m}$, wind speed of 1.72 to $5.48 \mathrm{~m} / \mathrm{s}$ and the average temperature was $26.74^{\circ} \mathrm{C}$, average $\mathrm{RH}$ was $48.88 \%$ and average pressure was $98915 \mathrm{~Pa}$. As shown in Figure 10, droplet density decreases as flight speed increases. For nozzle XR8001, the density at the "slow" speed was between 3 and 35 droplets $/ \mathrm{cm}^{2}$, and the density at the "fast" speed was between 0 and 28 droplets $/ \mathrm{cm}^{2}$. For nozzle XR8002, the density at the "slow" speed was between 7 and 35 droplets $/ \mathrm{cm}^{2}$ and the density at the "fast" speed was

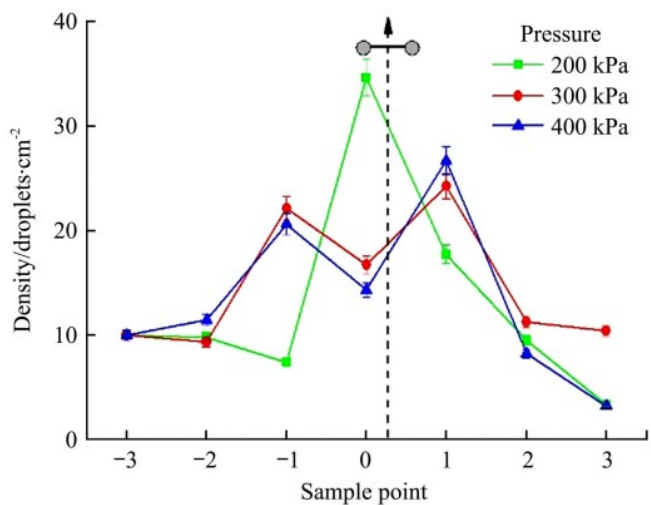

a. XR8001 Slow

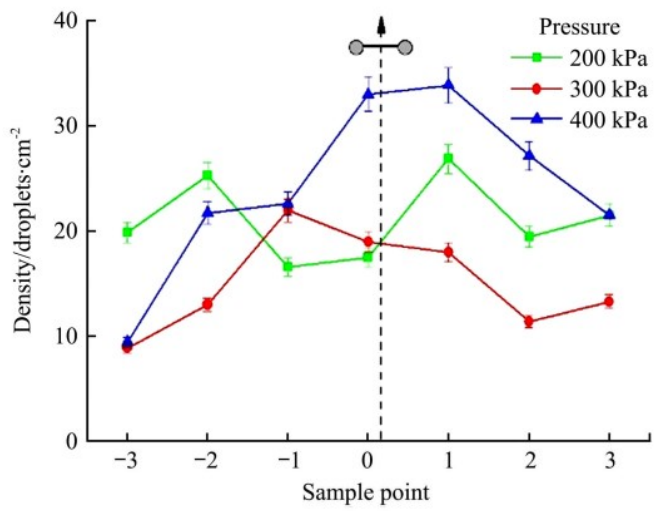

c. XR8002 Slow between 0 and 24 droplets $/ \mathrm{cm}^{2}$. For XR8001 at the "slow" speed in 200,300 , and $400 \mathrm{kPa}$, the number of sample cards over 10 droplets $/ \mathrm{cm}^{2}$ in density were 3,6 , and 5 ; the uniformities of droplet density were $78.7 \%, 41.8 \%$, and $58.6 \%$ respectively. For XR8001 at the "fast" speed in 200, 300, and $400 \mathrm{kPa}$, the number of sample cards over 10 droplets $/ \mathrm{cm}^{2}$ in density were 1, 2, and 3; the uniformities of droplet density were $69.7 \%, 85.0 \%$, and $80.6 \%$ respectively. For XR8002 at the "slow" speed in 200, 300, and $400 \mathrm{kPa}$, the number of sample cards over 10 droplets $/ \mathrm{cm}^{2}$ in density were 7,6 , and 6 ; the uniformities of droplet density were $18.3 \%, 31.0 \%$, and $34.3 \%$ respectively. For XR8002 at the "fast" speed in 200,300 , and $400 \mathrm{kPa}$, the number of sample cards over 10 droplets $/ \mathrm{cm}^{2}$ in density were 5,5 , and 2 ; the uniformities of droplet density were $66.3 \%, 58.0 \%$, and $93.6 \%$ respectively. Flight speed had a significant influence on droplet density; the "slow" flight speed was the optimal speed for nozzles XR8001 and XR8002, due to its association with a high droplet density.

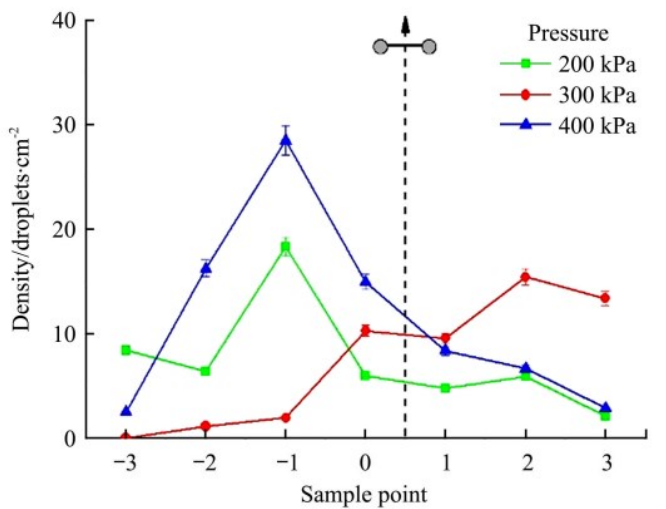

b. XR8001 Fast

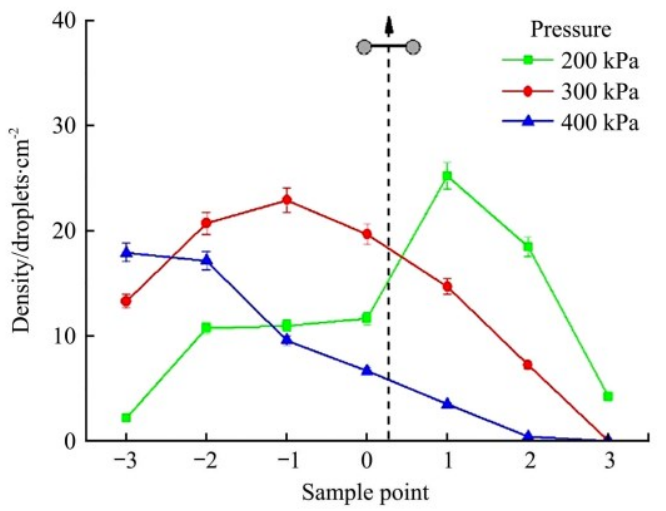

d. XR8002_Fast

Note: The flight path is indicated by the black dotted line, and the two grey dots represent the positions of the two nozzles.

Figure 10 Density (droplets $/ \mathrm{cm}^{2}$ ) at different sample points for various nozzle types and flight speed conditions 
Table 9 Flight and environmental data collected by the data acquisition system for Tests 1-12 in Series 3

\begin{tabular}{cccccccc}
\hline Tests & $\begin{array}{c}\text { Speed } \\
/ \mathrm{m} \cdot \mathrm{s}^{-1}\end{array}$ & $\begin{array}{c}\text { Height } \\
/ \mathrm{m}\end{array}$ & $\begin{array}{c}\text { Wind speed } \\
/ \mathrm{m} \cdot \mathrm{s}^{-1}\end{array}$ & $\begin{array}{c}\text { Wind } \\
\text { direction }\end{array}$ & $\begin{array}{c}\text { Temperature } \\
/{ }^{\circ} \mathrm{C}\end{array}$ & $\begin{array}{c}\mathrm{RH} \\
/ \%\end{array}$ & $\begin{array}{c}\text { Pressure } \\
/ \mathrm{Pa}\end{array}$ \\
\hline Test 1 & 3.54 & 0.76 & 1.80 & $\mathrm{SE}$ & 20.58 & 67.49 & 98957 \\
Test 2 & 3.81 & 0.74 & 2.92 & $\mathrm{~S}$ & 25.82 & 48.56 & 98975 \\
Test 3 & 3.80 & 0.85 & 2.98 & $\mathrm{SE}$ & 28.66 & 45.41 & 98975 \\
Test 4 & 3.88 & 0.69 & 2.96 & $\mathrm{SW}$ & 23.56 & 57.69 & 98951 \\
Test 5 & 3.66 & 0.84 & 2.18 & $\mathrm{NE}$ & 30.52 & 41.39 & 98825 \\
Test 6 & 4.07 & 0.83 & 2.62 & $\mathrm{~W}$ & 26.95 & 48.51 & 99315 \\
Test 7 & 7.75 & 0.98 & 5.48 & $\mathrm{NE}$ & 27.03 & 47.81 & 98822 \\
Test 8 & 7.66 & 1.05 & 1.72 & $\mathrm{E}$ & 28.92 & 45.03 & 98965 \\
Test 9 & 7.26 & 1.05 & 2.38 & $\mathrm{SW}$ & 26.10 & 48.68 & 98811 \\
Test 10 & 7.12 & 0.84 & 2.18 & $\mathrm{E}$ & 25.49 & 50.35 & 98770 \\
Test 11 & 7.78 & 1.25 & 2.55 & $\mathrm{E}$ & 30.74 & 38.91 & 98834 \\
Test 12 & 8.33 & 1.25 & 2.84 & $\mathrm{NE}$ & 26.53 & 46.74 & 98775 \\
\hline Note: RH represents relative humidity which describes the degree of drying
\end{tabular}

Note: RH represents relative humidity which describes the degree of drying.

3.3.3 Effect of flight speed on droplet deposition

The droplet deposition rate by sample point for nozzles

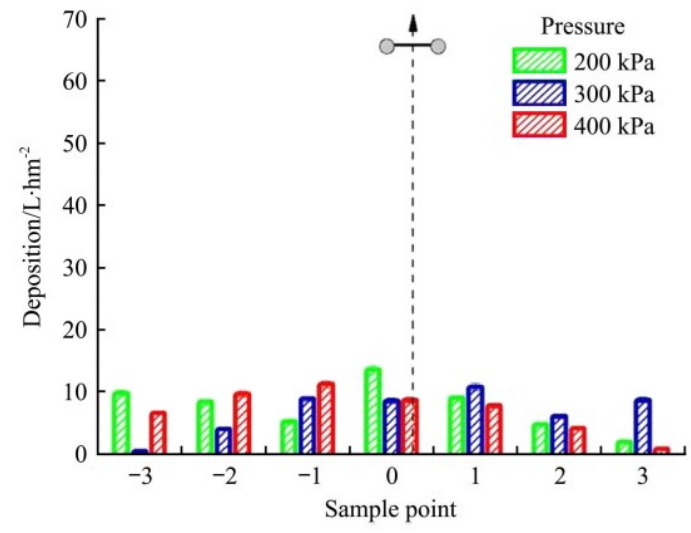

a. XR8001_Slow

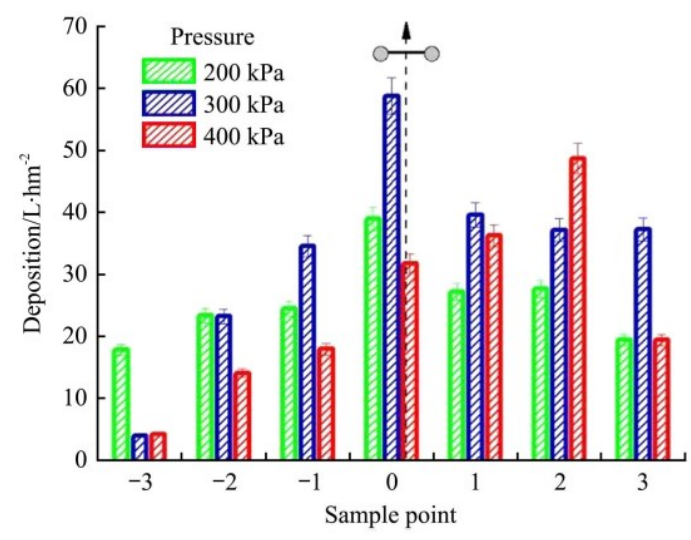

c. XR8002_Slow
XR8001 and XR8002 is shown in Figure 11 for different pressures. The $\mathrm{X}$-axis indicates the sample points and the $\mathrm{Y}$-axis represents droplet deposition. The different-colored columns represent the various pressures.

It is clear that flight speed has a significant influence on droplet deposition, which is consistent with the results of the density analysis described above. For nozzle XR8001, the deposition rate at the "slow" speed was between 0 and $13.6 \mathrm{~L} / \mathrm{hm}^{2}$ and that at the "fast" speed was between 0 and $4.2 \mathrm{~L} / \mathrm{hm}^{2}$. For nozzle XR8002, the deposition rate at the "slow" speed was between 4.05 and $58.85 \mathrm{~L} / \mathrm{hm}^{2}$ and that at the "fast" speed was between 0 and $25.25 \mathrm{~L} / \mathrm{hm}^{2}$. For XR8001 at the "slow" speed in 200,300 , and $400 \mathrm{kPa}$, the uniformities of droplet density were $51.1 \%, 52.4 \%$, and 50.3\% respectively. For XR8001 at the "fast" speed in 200,300 , and $400 \mathrm{kPa}$, the uniformities of droplet density were $54.2 \%, 61.8 \%$, and $55.9 \%$ respectively. For XR8002 at the "slow" speed in 200, 300, and $400 \mathrm{kPa}$, the uniformities of droplet density were $27.2 \%, 49.9 \%$, and $61.1 \%$ respectively. For XR8002 at the "fast" speed in 200, 300, and $400 \mathrm{kPa}$, the uniformities of droplet density were $66.3 \%, 58.0 \%$, and $93.6 \%$ respectively.

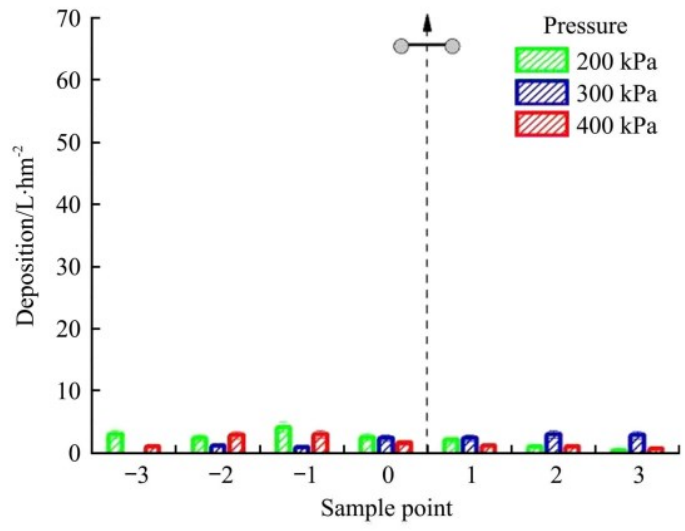

b. XR8001_Fast

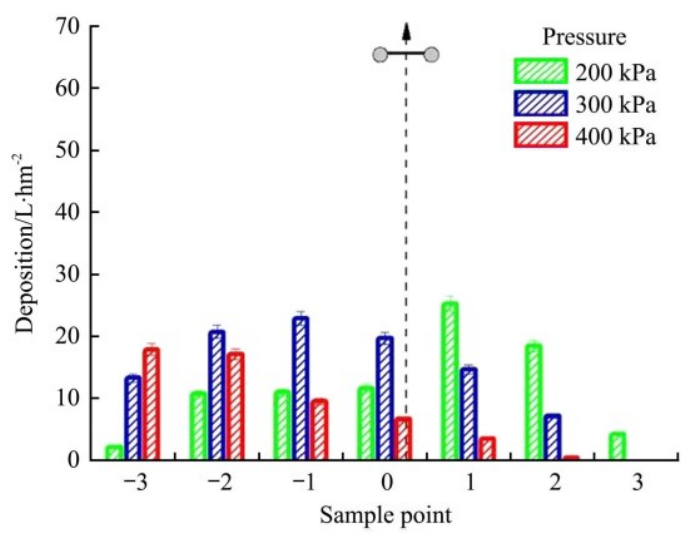

d. XR8002 Fast

Note: The flight path is indicated by the black dotted line, and the two grey dots represent the positions of the two nozzles.

Figure 11 Droplet deposition $\left(\mathrm{L} / \mathrm{hm}^{2}\right)$ at each sample point for different nozzle types and flight speed conditions

\subsubsection{Correlation matrix}

Table 10 is the correlation matrix from Series 3 . The inclusion of more recorded flight parameters increased the matrix size, so labels were assigned to single letters.

As seen in Table 10, there was a strong positive correlation between flow rate and deposition, flow rate and density, a negative correlation between DV and pressure. Besides, a moderate negative correlation between velocity and density, implying increased velocities result in lower application densities, which is to be expected. Although the droplet density and deposition were different between nozzles XR8001 and XR8002, they showed similar tendencies. Furthermore, the DV $\left(\mathrm{D}_{\mathrm{V} 0.1}, \mathrm{D}_{\mathrm{V} 0.5}, \mathrm{D}_{\mathrm{V} 0.9}\right)$ decreased as the nozzle pressure increased, and the droplet density and deposition rate decreased as the flight speed increased. Thus, the DV ( $\left.\mathrm{D}_{\mathrm{V} 0.1}, \mathrm{D}_{\mathrm{V} 0.5}, \mathrm{D}_{\mathrm{V} 0.9}\right)$ can be increased by reducing the spray pressure and droplet density, and the deposition rate can be increased by reducing the flight speed; however, this may, in turn, reduce the operation efficiency, as a larger proportion of the spray is deposited over a smaller area. 
Table 10 Series 3 correlation matrix

\begin{tabular}{|c|c|c|c|c|c|c|c|c|c|c|c|c|}
\hline Parameter & A & B & $\mathrm{C}$ & $\mathrm{D}$ & $\mathrm{E}$ & $\mathrm{F}$ & G & $\mathrm{H}$ & I & $\mathrm{J}$ & $\mathrm{K}$ & $\mathrm{L}$ \\
\hline A & 1 & -0.01 & 0.41 & 0.20 & 0.13 & -0.16 & 0.21 & -0.39 & -0.69 & -0.69 & 0.70 & 0.73 \\
\hline B & -0.01 & 1 & 0.40 & -0.18 & 0.43 & -0.48 & -0.37 & -0.55 & -0.43 & -0.27 & 0.08 & -0.06 \\
\hline $\mathrm{C}$ & 0.41 & 0.40 & 1 & 0.05 & 0.51 & -0.57 & -0.09 & -0.06 & -0.59 & -0.38 & -0.56 & -0.36 \\
\hline $\mathrm{D}$ & 0.20 & -0.18 & 0.05 & 1 & 0.06 & -0.13 & -0.05 & 0.04 & -0.17 & -0.22 & -0.47 & -0.19 \\
\hline $\mathrm{E}$ & 0.13 & 0.43 & 0.51 & 0.06 & 1 & -0.97 & -0.13 & -0.32 & -0.53 & -0.26 & -0.15 & 0.17 \\
\hline $\mathrm{G}$ & 0.21 & -0.37 & -0.09 & -0.05 & -0.13 & 0.17 & 1 & -0.06 & -0.30 & -0.47 & -0.47 & -0.38 \\
\hline $\mathrm{H}$ & -0.39 & -0.55 & -0.06 & 0.04 & -0.32 & 0.36 & -0.06 & 1 & 0.69 & 0.59 & -0.10 & 0.26 \\
\hline I & -0.69 & -0.43 & -0.59 & -0.17 & -0.53 & 0.59 & -0.30 & 0.69 & 1 & 0.9 & 0.59 & 0.63 \\
\hline $\mathrm{J}$ & -0.69 & -0.27 & -0.38 & -0.22 & -0.26 & 0.33 & -0.47 & 0.59 & 0.9 & 1 & 0.66 & 0.84 \\
\hline $\mathrm{K}$ & 0.70 & 0.08 & -0.56 & -0.47 & -0.15 & 0.19 & -0.47 & -0.10 & 0.59 & 0.66 & 1 & 0.73 \\
\hline $\mathrm{L}$ & 0.73 & -0.06 & -0.36 & -0.19 & 0.17 & -0.08 & -0.38 & 0.26 & 0.63 & 0.84 & 0.73 & 1 \\
\hline
\end{tabular}

Note: A represents flow rate; $\mathrm{B}$ represents pressure; C represents height; D represents velocity; E represents temperate; F represents humidity; G represents barometric pressure; $\mathrm{H}$ represents $\mathrm{D}_{\mathrm{V} 0.1}$; I represents $\mathrm{D}_{\mathrm{V} 0.5} ; \mathrm{J}$ represents $\mathrm{D}_{\mathrm{V} 0.9} ; \mathrm{K}$ represents density; L represents deposition.

\section{Conclusions}

In this study, a UAAS for chemical spraying based on the DJI S1000 octocopter was built, and a data acquisition system was used to assess the performance of the UAAS under various flight and droplet application conditions. The information obtained from these experiments provided valuable insight into the feasibility of multirotor UAAS for chemical application.

Comprehensive tests were conducted to evaluate the spray performance. The analysis suggested that the droplet distribution did not vary significantly by nozzle type under optimal application conditions, although there were some notable variations, especially in DV. The overlapping region between the two nozzles of the UAAS can be controlled by adjusting the nozzle spacing, to maximize the spraying effectiveness. Droplet drift and inaccurate application can be minimized by decreasing the nozzle pressure or using a larger nozzle to produce coarser droplets. Large droplets, which were not affected by airflow, tended to be deposited in the region closest to the center of the UAAS. The flight speed plays an important role in spray performance. When applied height was at or below the recommended application, the smallest effective pattern width and highest CV were produced. These characteristics highlight the importance of accurate height control if applying with this nozzle type.

As a result, poor positioning could have a very drastic effect on the uniformity of overall application. GPS systems, which are currently the most common method of positioning outdoors, generally have accuracies in the scale of meters, so given a 2-3 m pattern width. This represents a very large window for error and potential for a relatively non-uniform application. GPS is not likely to be suitable on its own for a multirotor UAAS spray system used as a broadcast applicator, and a more accurate positioning system would be required as well.

The downwash airflow of the UAAS rotors may improve coverage on the leaf surfaces of plants. Larger droplets from these nozzles tended to deposit in the region closer to the UAAS center, increasing the droplet volume in this region, with droplet volume gradually decreasing in the region of the effective swath and then sharply decreasing outside this area, being attributed to downwash outflow. As a result, the data and analyses of this study provide insight into the feasibility of multirotor UAAS for pesticide application and could aid in maximizing efficacy, reducing drift, and minimizing damage to other organisms.

\section{Acknowledgements}

The authors acknowledge TeeJet and Becky May for the donation of materials essential to the completion of this project and DJI for the donation of the UAS platform on which the spray system was built. This work was partially financially supported by the National Key Research and Development Program of China (Grant No. 2016YFD0200701).

\section{[References]}

[1] Zhang C, Kovacs J. The application of small unmanned aerial systems for precision agriculture: A review. Precision Agriculture, 2012; 13: 693-712.

[2] Zhang N, Wang $M$, Wang N. Precision agriculture-A worldwide overview. Computers and Electronics in Agriculture, 2002; 36(2-3): $113-132$.

[3] Senthold A, Frank A. Future farms without farmers. Science Robotics, 2019; 4(27): 1875 . doi: 10.1126/scirobotics.aaw1875.

[4] Faical B S, Costa F G, Pessin G, Ueyama J, Freitas H, Colombo A. The use of unmanned aerial vehicles and wireless sensor networks for spraying pesticides. Journal of Systems Architecture, 2014; 60: 393-404.

[5] Kim J, Kim S, Ju C, Son H I. Unmanned aerial vehicles in agriculture: a review of perspective of platform, control, and applications. IEEE Access, 2019; 7: 105100-105115.

[6] Zhou Z, Zang Y, Luo X, Lan Y, Xue X. Technology innovation development strategy on agricultural aviation industry for plant protection in China. Transactions of CSAE, 2013; 29: 1-10. (in Chinese)

[7] Zhang C, Kovacs J M. The application of small unmanned aerial systems for precision agriculture: A review. Precision Agriculture, 2012; 13: 693-712.

[8] Shamshiri R R, Hameed I A, Balasundram S K, Ahmad D, Weltzien C, Yamin M. Fundamental research on unmanned aerial vehicles to support precision agriculture in oil palm plantations. INTECH: Agricultural Robots: Fundamentals and Applications, 2018; pp.91-116.

[9] Balasundram S K, Golhani K, Shamshiri R R, Vadamalai G. Precision agriculture technologies for management of plant diseases. In Plant Disease Management Strategies for Sustainable Agriculture through Traditional and Modern Approaches. Springer: Sustainability in Plant and Crop Protection, 2020; pp.259-278. doi: 10.1007/978-3-030-35955-3_13.

[10] Yang S, Yang X, Mo J. The application of unmanned aircraft systems to plant protection in China. Precision Agriculture, 2018; 19: 278-292.

[11] Huang Y, Thomson S J, Hoffman W C, Lan Y, Fritz B K. Development and prospect of unmanned aerial vehicle technologies for agricultural production management. International Journal of Agricultural and Biological Engineering, 2013; 6: 1-10.

[12] Yang C. Remote sensing and precision agriculture technologies for crop disease detection and management with a practical application example. Engineering, 2019; 10: 015. doi: 10.1016/j.eng.2019.10.015.

[13] Zhang H, Wang X, Chen Y, Jiang G, Lin S. Research on vision-based navigation for plant-protection UAV under the near color background. Symmetry, 2019; 11: 533 . doi: 10.3390/sym11040533 
[14] Wang S, Han Y, Chen J, Du N, Pan Y, Wang G. Flight safety strategy analysis of the plant protection UAV. IFAC Papers online, 2018; 21: 262-267.

[15] Wen S, Zhang Q, Deng J, Lan Y, Yin X, Shan J. Design and experiment of a variable spray system for unmanned aerial vehicles based on PID and PWM control. Applied Sciences, 2018; 8(12): 2482. doi: 10.3390/ app8122482.

[16] Huang Y, Hoffmann W C, Lan Y, Wu W, Fritz B K. Development of a spray system for unmanned aerial vehicle platform. Applied Engineering in Agriculture, 2009; 25(6): 803-809.

[17] Thomson S J, Womac A R, Mulrooney J E. Reducing pesticide drift by considering propeller rotation effects from aerial application near buffer zones. Sustainable Agriculture Research, 2013; 2(3): 41-51.

[18] Brown C R, Giles D K. Measurement of pesticide drift from unmanned aerial vehicle application to a vineyard. Transactions of ASABE, 2018; 61: $1539-1546$

[19] Ru Y, Jin L, Zhou H P, Jia Z C. Performance experiment of rotary hydraulic atomizing nozzle for aerial spraying application. Transactions of the CSAE, 2014; 30(3): 50-55. (in Chinese)

[20] Nuyttens D D S M, Baetens K, Brusselman E, Dekeyser D, Verboven P. Drift from field crop sprayers using an integrated approach: Results of a 5-year study. Transactions of the ASABE, 2011; 54(2): 403-408.

[21] Ansara N, Parvez M, John S P, John D, Arko L, Mirek M. Portable device for continuous sensing with rapidly pulsed LEDs - Part 1: Rapid on-the-fly processing of large data streams using an open source microcontroller with field programmable gate array. Measurement, 2019; 146: 749-757.

[22] Cos C R, Acosta J A, Ollero A. Adaptive integral inverse kinematics control for lightweight compliant manipulators. IEEE Robotics and Automation Letters, 2020; 5: 3468-3474.

[23] Wendel J, Meister O, Schlail E C, Trommer G F. An integrated GPS/MEMS-IMU navigation system for an autonomous helicopter. Aerospace Science and Technology, 2006; 10: 527-533.

[24] Peng Y, Liu X, Sun Z, Ji C, Li L, Wu Z. Exploiting the bulk photovoltaic effect in a $2 \mathrm{D}$ trilayered hybrid ferroelectric for highly sensitive polarized light detection. Angewandte Chemie, 2020; 132: 3961-3965.

[25] Mestre G, Ruano A, Duarte H, Silva S, Khosravani H, Pesteh S. An intelligent weather station. Sensors, 2015; 15: 31005-31022.

[26] Hojaiji H, Kalantarian H, Bui A T, King C E, Sarrafzadeh M. Temperature and humidity calibration of a low-cost wireless dust sensor for real-time monitoring. In: 2017 IEEE Sensors Applications Symposium (SAS). Glassboro, NJ, USA: IEEE, 2017; 7894056. doi: 10.1109/SAS.2017.7894056

[27] Jan S, Chen Y. Establishing unusual-weather detection system prototype using onboard sensor information. In: American Institute of Aeronautics and Astronautics (AIAA), 2019; pp.1281-1290. doi: 10.2514/1.C034630.

[28] Wang G, Li Y. Parabolic PWM for current control of voltage-source converters (VSCs). International Journal of Renewable Energy Research, 2010; 57(10): 3491-3496.

[29] Aragon J D, Morgado E A, Perez P F. Low-cost servomotor driver for PFM control. Sensors, 2018; 18(1): 93 . doi: 10.3390/s18010093.

[30] Chuang SY, Sahoo N, Lin H, Chang Y. Predictive maintenance with sensor data analytics on a Raspberry Pi-based experimental platform. Sensors, 2019; 19(18): 3884 . doi: 10.3390/s19183884.

[31] Wilkes TC, McGonigle A J S, Pering T D, Taggart A J, White BS, Bryant R G. Ultraviolet imaging with low cost smartphone sensors: development and application of a Raspberry Pi-based UV camera. Sensors, 2016; 16(10): 1649. doi: 10.3390/s16101649

[32] Olivier B. Pyo, the Python DSP toolbox. Journal of Machine Learning Research, 2016; 16:1214-1217. doi: 10.1145/2964284.2973804.

[33] Wang J, Lan Y, Zhang H, Zhang Y, Wen S, Yao W. Drift and deposition of pesticide applied by UAV on pineapple plants under different meteorological conditions. International Journal of Agricultural and Biological Engineering, 2018; 11(6): 5-12.

[34] Li J, Lan Y, Wang J. Distribution law of rice pollen in the wind field of small UAV. International Journal of Agricultural and Biological Engineering, 2017; 10(4): 32-40.

[35] Zhang Y, Li Y, He Y, Liu F, Cen H, Fang H. Near ground platform development to simulate UAV aerial spraying and its spraying test under different conditions. Computer and Electronics in Agriculture, 2017; 148: $8-18$.

[36] Arvidsson T, Bergstrom L, Kreuger J. Spray drift as influenced by meteorological and technical factors. Pest Management Science, 2011; 67: 586-598.

[37] Lechoczki K S, Toth B, Kotai C, Martonosi I, Farady L, Kondrak L. Chemical control of FHB in wheat with different nozzle types and fungicides. Cereal Research Communications, 2008; 36: 677-681.

[38] Creech C F, Henry R S, Fritz B K, Kruger G R. Influence of herbicide active ingredient, nozzle type, orifice size, spray pressure, and carrier volume rate on spray droplet size characteristics. Weed Technology, 2015 29: 298-310.

[39] Boller W, Machry M. Operating pressure and spray nozzles effects on the efficiency of contact herbicide in soybeans. Engenharia Agricola, 2007; 27: 722-727.

[40] Schneider J L, Oliveira G M, Balan R E, Canteri MG, Saab O J. Spray droplet coverage achieved with different nozzles and application rates in the aerial part of sugar cane. Ciencia Rural, 2013; 43: 797-802.

[41] Post S L, Roten R L, Connell R J. Discharge coefficients of flan-fan nozzles. Transactions of the ASABE, 2017; 60: 347-351.

[42] Fox R D, Derksen R C, Cooper J A, Krause C R, Ozkan H E. Visual and image system measurement of spray deposits using water-sensitive paper. Applied Engineering in Agriculture, 2003; 19(5): 549-552.

[43] Thompson S J, Lyu M E. Environmental and spray mixture effects on deposit size represented by water-sensitive paper used in drift studies. Transactions of the ASABE, 2011, 54: 803-807.

[44] Hoffman W C, Hewitt A J. Comparison of three imaging systems for water-sensitive papers. Applied Engineering in Agriculture, 2005, 21: 961-964.

[45] Zhu H, Salyani M, Fox R D. A portable scanning system for evaluation of spray deposit distribution. Computers and Electronics in Agriculture, 2011, 76: 38-43.

[46] Chen S, Lan Y, Zhou Z, Ou Y, Wang G, Huang X. Effect of Droplet Size Parameters on Droplet Deposition and Drift of Aerial Spraying by Using Plant Protection UAV. Agronomy, 2020, 10: 195. doi: 10.3390/ agronomy10020195.

[47] Joao P A R, Elton F R, Heli H T A, Thiago N L. Evaluation of Droplet Spectra of the Spray Tip AD 11002 Using Different Techniques. Engenharia Agricola 2019, 39: 476-481.

[48] Lyu M, Xiao S, Yu T, He Y. Influence of UAV flight speed on droplet deposition characteristics with the application of infrared thermal imaging. Int J Agric \& Biol Eng, 2019; 12(3): 10-17. 